Elton Vitoriano Ribeiro

\title{
A questão da Intersubjetividade no pensamento ético-filosófico de H. C. de Lima Vaz
}

\section{DISSERTAÇÃO DE MESTRADO}

\section{DEPARTAMENTO DE FILOSOFIA Programa de Pós-Graduação em Filosofia}




\title{
Pontifícia Universidade Católica \\ Do Rio de Janeiro
}

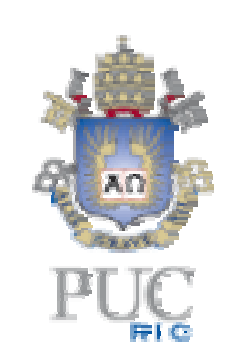

\section{Elton Vitoriano Ribeiro}

\section{A questão da Intersubjetividade no pensamento ético filosófico de H. C. de Lima Vaz}

\author{
Dissertação de Mestrado \\ Dissertação apresentada como requisito parcial para obtenção do grau de \\ Mestre pelo Programa de Pós-graduação em Filosofia do Departamento \\ de Filofosia da Puc-Rio.
}

Orientador: Prof. Dr. Edgar J. Jorge Filho 
Todos os direitos reservados. É proibida a reprodução total ou parcial do trabalho sem autorização da universidade, do autor e do orientador.

Ficha Catalográfica

Ribeiro, Elton Vitoriano

A questão da intersubjetividade no pensamento ético filosófico de $\mathrm{H}$. C. de Lima Vaz / Elton Vitoriano Ribeiro; orientador: Edgar J. Jorge Filho. - Rio de Janeiro : PUC, Departamento de Filosofia, 2003.

[11], 154 f. ; $30 \mathrm{~cm}$

Dissertação (mestrado) - Pontifícia Universidade Católica do Rio de Janeiro, Departamento de Filosofia.

Inclui referências bibliográficas.

1. Filosofia - Teses. 2. Ética. 3. Cultura. 4. Comunidade ética. 5. Justiça. I. Jorge Filho, Edgard J. II. Pontifícia Universidade Católica do Rio de Janeiro. Departamento de Filosofia. III. Título.

CDD: 100 


\section{Dedicatória}

Tal qual o óbolo da viúva (Lc. 21, 1-4), minha homenagem ao Padre Henrique Cláudio de Lima Vaz sj. Dialeticamente: Companheiro Mestre - Irmão. 


\section{Agradecimentos}

Ao Professor Doutor Edgar José Jorge Filho pela sua prestativa e atenciosa orientação.

Aos professores, alunos e amigos do Departamento de Filosofia da PUC Rio.

Ao CNPq pelos auxílios concedidos.

Aos meus irmãos jesuítas da Residência Padre Leonel Franca da PUC Rio pela convivência fraterna.

A Deus, criador inefável, fonte suprema de sentido, pela superabundância e infinita generosidade do dom da vida. 


\section{Resumo}

A questão ética se apresenta como a questão de todos nós. Por isso, pensar nossas relações éticas com-os-outros-no-mundo é fundamental para uma vivência plena da existência humana. Nesta dissertação, temos como objetivo refletir sobre o lugar e a arquitetônica da categoria de intersubjetividade no pensamento ético filosófico de H. C. de Lima Vaz. Para alcançar tal intento, faz-se necessário situar a questão no conjunto do pensamento ético de Lima Vaz. Daí a análise do ethos, da cultura e da racionalidade. Deste conjunto de tópicos surge a problemática da intersubjetividade, isto é, da comunidade ética, comunidade de reconhecimento e consenso, e de sua plena realização na justiça.

Palavras-chave: ethos, cultura, comunidade ética, reconhecimento, consenso, justiça. 


\begin{abstract}
The ethical question is posed as a question for everyone. As a result, thinking about our ethical relationships with-others-in-the-world is of fundamental importance for fulfillment of human existence. In this thesis we intend to reflect about the place and shape of intersubjectivity in the ethical and philosophical thought of H. C. de Lima Vaz. For this, it is necessary to locate this problem within the whole ethical thought of Lima Vaz. So, we undertake the analysis of the ethos, culture, and rationality. From these topics the problem of the intersubjectivity follows emerges, that is, the problem of ethical community, community of recognition and concensus, and its fulfillment in justice.
\end{abstract}

Key-words: ethos, culture, ethical community, recognition, consensus, justice. 


\section{Sumário}

Introdução

Parte I: Temas Fundamentais da arquitetônica do pensamento ético-filosófico de Lima Vaz

Capítulo I - O Ethos

1. Fenomenologia da ethos 28

2. Do Ethos à Ética 37

3.Da Estruturação do Campo ético 46

Capítulo II - A Cultura $\quad 54$

1. Fenomenologia da Cultura 54

2. Ontologia da Cultura 61

3. Ética da Cultura $\quad 67$

Capítulo III - A Racionalidade do ethos 72

1. A Razão Prática 73

2. Níveis de compreensão da Razão prática 74

3. O movimento dialético da Razão prática 80

$\begin{array}{ll}\text { Conclusão da Primeira Parte } & 83\end{array}$

Parte II - A arquitetônica da categoria da intersubjetividade 86 como lugar de realização ética do ser humano

Capítulo IV - Prolegômenos à problemática da 87 intersubjetividade ética

1. A Filosofia 88

2. Aspectos da problemática antropológica da intersubjetividade 91 
Capítulo V - A comunidade de reconhecimento e consenso

como lugar de realização da intersubjetividade ética

1. Reconhecimento e Consenso 97

2. A Comunidade Ética 105

3. A Consciência Moral Social 113

Capítulo VI - A categoria de justiça como elemento intrínseco à 121 realização da comunidade ética na vida da comunidade humana, ou, Viver eticamente é viver uma vida justa

1. A Justiça 121

2. Situações de realização da comunidade ética na justiça 129

3. A Dignidade Humana 136

$\begin{array}{ll}\text { Conclusão da Segunda Parte } & 139\end{array}$

À Guisa de Conclusão 141

Referências Bibliográficas 152

$\begin{array}{ll}\text { Índice } & 160\end{array}$ 


\section{Abreviações das obras de H. C. de Lima Vaz}

\begin{tabular}{|l|l|}
\hline EF I & Problemas de Fronteira, 1986. \\
\hline EF II & Ética e Cultura, 1988. \\
\hline EF III & Filosofia e Cultura, 1997. \\
\hline EF IV & Introdução à Ética Filosófica I, 1999. \\
\hline EF V & Introdução à Ética Filosófica II, 2000. \\
\hline EF VI & Ontologia e História (segunda edição), 2001. \\
\hline EF VII & Raízes da Modernidade, 2002. \\
\hline AF I & Antropologia Filosófica I, 1991. \\
\hline AF II & Antropologia Filosófica II, 1992. \\
\hline MF & Experiência Mística e Filosófica da Tradição Ocidental, 2000. \\
\hline
\end{tabular}


"Numa sociedade como a do Brasil atual, estou convencido de que a vocação do filósofo vem carregada com uma enorme responsabilidade social".

H. C. de Lima Vaz

(O problema da Filosofia no Brasil)

“Quem é capaz de ver o todo, é filósofo; quem não é capaz, não o é”.

Platão

(República) 